\title{
O POSITIVISMO JURÍDICO DE HANS KELSEN
}

\author{
HANS KELSEN'S LEGAL POSITIVISM
}

\author{
Maurício Avila Prazak* \\ Marcelo Negri Soares** \\ Ueslen da Silva***
}

\begin{abstract}
RESUMO
O presente artigo tem como por objetivo a análise do Positivismo Jurídico de Hans Kelsen e a sua Teoria do Direito. Para dar início a essa análise, começaremos discorrendo sobre a estrutura hierárquica da Constituição como norma fundamental, seguindo no tópico abaixo onde entraremos no assunto do positivismo e depois passaremos a analisar sua validade e eficácia. Hans Kelsen também foi muito criticado por juristas em todo o mundo, tendo em vista que a sua obra Teoria pura do direito não estaria isenta de ideologias e sua formalidade. Para melhor entendimento dos tópicos explanados, passaremos a abordar os elementos do fato jurídico e interpretação o ato jurídico e, por fim, e não menos importante, vamos entender o sistema normativo por meio da pirâmide de Hans Kelsen, que por sinal é bastante visado na graduação. Este artigo utiliza-se do método hipotético dedutivo, em análise doutrinária, legal e jurisprudencial, a fim de resolver as indagações previstas nesta pesquisa.
\end{abstract}

PALAVRAS-CHAVE: Positivismo. Eficácia. Norma Fundamental. Validade. Fato Jurídico.

\begin{abstract}
This article aims to analyze Hans Kelsen's Legal Positivism and his Theory of Law. To begin this analysis, we will start by discussing the hierarchical structure of the Constitution as a fundamental norm, following the topic below where we will enter the subject of positivism and then we will begin to analyze its validity and effectiveness. Hans Kelsen was also widely criticized by jurists around the world, considering that his work Pure Theory of Law would not be exempt from ideologies and its formality. For a better understanding of the topics explained, we will begin to address the elements of the legal fact and interpretation the legal act and finally, and not least we will understand the normative system through the pyramid of Hans Kelsen, which by the way is quite targeted at graduation. This article uses the hypothetical deductive method, in doctrinal, legal and jurisprudential analysis, in order to resolve the questions provided for in this research.
\end{abstract}

KEYWORDS: Positivism; Effectiveness; Fundamental Norm; Validity; Juridical Fact.

\footnotetext{
* Doutor em direito. Professor na Escola Paulista de Direito. E-mail: mauricio.prazak@ibrei.org.

** Doutor em direito. Professor do Programa de Mestrado e Doutorado em Direito UniCesumar. E-mail: negri@negrisoares.com.br.

${ }^{* * *}$ Mestrando em Soluções Alternativas de Controvérsias Empresariais na Escola Paulista de Direito - EPD. Email: Ueslen.silva@nokia.com.
} 


\section{INTRODUÇÃO}

Hans Kelsen nasceu em Praga, em 1881 e faleceu em 1973, nos Estados Unidos. Foi considerado por muitos o maior jurista do século XX. Com medo das perseguições de Hitler, ele se mudou para os Estados Unidos, obtendo grande reconhecimento mundial.

A Teoria pura do direito é a sua obra mais importante, com grande contribuição ao positivismo jurídico. No Positivismo, o conhecimento está restrito aos fatos e leis que o regem, não envolvendo a razão ou religião.

Esses são os problemas de pesquisa que pretendemos, com esteio no método hipotético-dedutivo, em análise doutrinária, legal e jurisprudencial, resolver neste artigo.

\section{POSITIVISMO JURÍDICO}

Para o Positivismo, a ciência é a única confiável, e outros conhecimentos provenientes de outras fontes seriam postos de lado; para a Teoria Pura do Direito de Hans Kelsen, deveria ser livre de considerações políticas, econômicas, filosóficas ou mesmo éticas.

O seu sistema teria como base o direito positivo, admitindo a possibilidade de justificar o direito apenas com noções jurídicas. Além disso, a Teoria de Hans Kelsen consideraria um conjunto de normas vinculado com sanções.

A relação em que a conduta de uma pessoa está com uma ou várias outras pessoas pode ser imediata ou mediata. O homicídio é uma conduta do homicida em face da vítima. E uma relação imediata de homem a homem. Quem destrói um objeto valioso, atua imediatamente em face de uma coisa e mediatamente em face de uma ou várias pessoas que estão interessadas nessa coisa, especialmente se ela é propriedade dessas pessoas. Uma ordem normativa que regula a conduta humana quando ela está em relação com outras pessoas é uma ordem social. A Moral e o Direito são ordens sociais desse tipo.

A lógica tem por objeto uma ordem normativa que não tem qualquer caráter social, pois os atos de pensar do homem, que as normas desta ordem regulam, não afetam outras pessoas, o homem não pensa "perante" outro homem da mesma forma que atua em face de outro homem. A conduta que uma pessoa observa perante uma ou várias outras pessoas pode ser prejudicial ou útil a esta ou estas pessoas.

A doutrina positivista tem o seu apego ao formalismo legal, e a norma jurídica o seu eixo de sustentação. Os idealistas exprimem juízos de valor, enquanto os positivistas juízos 
de realidade, transpondo a investigação jurídica, os métodos das ciências naturais (BOBBIO, 1995, p. 23). Podemos indicar diferentes escolas dentro do positivismo jurídico, podemos ir desde as mais radicais às liberais, sempre com uma linha de pensamento semelhante, o tecnicismo formal, limitando-se a identificar o direito com a lei, mediante uma interpretação literal dos preceitos normativos.

Quanto à justiça, consideram apenas a legal, mesmo porque não existiria a chamada justiça absoluta. $\mathrm{O}$ ato da justiça consiste na aplicação da regra ao caso concreto. Os positivistas não aceitam a influência dos elementos extralegem na definição do Direito Objetivo.

O dever-ser e o ser de Hans Kelsen são descritos como distintos e independentes, o direito integra a realidade do dever-ser, as normas ditam como deve ser a conduta social ao poder estatal. Para Hans Kelsen (1999, p. 4):

\footnotetext{
Norma é o sentido de um ato através do qual uma conduta é prescrita, permitida ou, especialmente, facultada, no sentido de adjudicada à competência de alguém. Neste ponto é importante salientar que a norma, como o sentido específico de um ato intencional dirigido à conduta de outrem, é qualquer coisa de diferente do ato de vontade cujo sentido ela constitui.

$\mathrm{Na}$ verdade, a norma é um dever-ser e ao ato de vontade de que ela constitui sentido é um ser. Por isso, a situação fática perante a qual nos encontramos na hipótese de tal ato tem de ser descrita pelo enunciado seguinte: um indivíduo quer que o outro se conduza de determinada maneira.

A primeira parte refere-se a um ser, o ser fático do ato de vontade; a segunda parte refere-se a um dever-ser, a uma norma como sentido do ato.
}

Conforme o modo pelo qual as ações humanas são prescritas ou proibidas, podem distinguir-se diferentes tipos, tipos ideais, não tipos médios. A ordem social pode prescrever uma determinada conduta humana sem ligar à observância ou não observância desse imperativo quaisquer consequências. Também pode, porém, estatuir uma determinada conduta humana e, simultaneamente, ligar a essa conduta a concessão de uma vantagem, de um prêmio, ou ligar à conduta oposta uma desvantagem.

O princípio que conduz a reagir a uma determinada conduta com um prêmio ou uma pena é o princípio retributivo (Vergeltung). O prêmio e o castigo podem compreender-se no conceito de sanção. No entanto, designa-se por sanção somente a pena, isto é, um mal, a privação de certos bens como a vida, a saúde, a liberdade, a honra, valores econômicos, a aplicar como consequência de uma determinada conduta, mas já não o prêmio ou a recompensa (KELSEN, 1999, p. 17).

Até o século XVIII, o direito foi definido em duas espécies de direito, o natural e o 
positivo. Norberto Bobbio (1995) fornece seis critérios para distinguir o direito natural e o direito positivo:

$1^{\circ}$ ) baseado na antítese universalidade e particularidade: o direito natural vale em toda a parte, o direito positivo vale em alguns lugares;

$2^{\circ}$ ) baseado na antítese imutabilidade e mutabilidade: o direito natural é imutável no tempo, o direito positivo é mutável;

$3^{\circ}$ ) baseado na fonte do direito: o direito natural deriva da natureza racional, o direito positivo é aquele posto pelo Estado;

$4^{\circ}$ ) baseado no modo pelo qual o direito é conhecido pelos destinatários: o direito natural é aquele que é conhecido pelo uso da razão, o direito positivo, por uma declaração de vontade alheia;

$5^{\circ}$ ) baseado no objeto: os comportamentos regulados pelo direito natural são bons ou maus por si mesmos, enquanto os regulados pelo direito positivo são por si mesmo indiferentes e assumem uma qualificação;

$6^{\circ}$ ) baseado na valoração das ações: o direito natural estabelece aquilo que é bom, o direito positivo, aquilo que é útil.

$\mathrm{Na}$ época clássica, o direito natural era conhecido como direito comum, e o direito positivo, como direito especial ou particular. Assim, com base no princípio pelo qual o direito especial prevalece sobre o geral, o direito positivo prevalecia sobre o natural sempre que entre ambos ocorresse um conflito.

Segundo Bobbio (1995), haveria uma redução de todo o direito a um direito positivo no momento da formação do Estado Moderno, saindo o direito natural desta categoria. $\mathrm{O}$ Positivismo Jurídico passa a ser visto como uma doutrina segundo a qual não existe outro direito senão o positivo, concentrando no Estado todos os poderes, inclusive o de criar o direito, também sendo o único a estabelecer o direito, ou através da lei ou através do reconhecimento e controle das normas consuetudinárias. Nesse contexto, surge o Positivismo Jurídico, que viria a dominar o pensamento jurídico durante os séculos XIX e $\mathrm{XX}$.

O ideal de segurança perseguido pelo Estado Moderno foi moldado com base na insegurança das relações sociais sentida a partir da Reforma, quando, num mesmo espaço geográfico, passaram a conviver indivíduos com diferentes visões de mundo. A sociedade moderna é marcada pela ausência de valores objetivos que recebem a adesão generalizada.

A questão é que a segurança ficava comprometida se se recorresse ao subjetivismo 
dos juízos de valor (justiça, moral) ou à imponderabilidade da normatividade oriunda da simples atuação do poder (eficácia, política) para a resolução dos conflitos de interesses daquela sociedade.

O apelo à justiça, entendida como qualquer qualidade ético-política que torne uma norma merecedora de obediência, é visto como fator de insegurança na identificação do jurídico, pois os valores, formadores do âmbito moral da vida social, carecem de um conteúdo objetivo.

A segurança depende da objetividade e da previsibilidade na identificação do jurídico. O Estado Moderno vem fornecer um padrão objetivo de resolução de conflitos — a lei — a uma sociedade em conflito. A lei é um comando do soberano, identificada como jurídica pela sua origem e não pelo conteúdo. Ela pode ser justa ou injusta sem que isso afete a sua qualificação jurídica.

\section{A ESTRUTURA ESCALONADA DA ORDEM JURÍDICA — A CONSTITUIÇÃO}

A Constituição, que regula a produção de normas gerais, pode também determinar o conteúdo das futuras leis. E as Constituições positivas não raramente assim procedem ao prescrever ou ao excluir determinados conteúdos. No primeiro caso, geralmente apenas existe uma promessa de leis a fixar e não qualquer obrigação de estabelecer tais leis, pois, já mesmo por razões de técnica jurídica, não pode facilmente ligar-se uma sanção ao não estabelecimento de leis com o conteúdo prescrito. Com mais eficácia, porém, podem ser excluídas pela Constituição leis de determinado conteúdo.

O catálogo de direitos e liberdades fundamentais, que forma uma parte substancial das modernas constituições, não é, na sua essência, outra coisa senão uma tentativa de impedir que tais leis venham a existir. E eficaz quando pelo estabelecimento de tais leis, exemplo, leis que violem a chamada liberdade da pessoa ou de consciência, ou a igualdade, se responsabiliza pessoalmente determinado órgão que participa na criação dessas leis, chefe do Estado, ministros ou existe a possibilidade de atacá-las e anulá-las. Tudo isso sob o pressuposto de que a simples lei não tenha força para derrogar a lei constitucional que determina a sua produção e o seu conteúdo, de que esta lei somente possa ser modificada ou revogada sob condições mais rigorosas, como sejam uma maioria qualificada ou um quórum mais amplo. Quer isso dizer que a Constituição prescreve para a sua modificação ou supressão um processo mais exigente, diferente do processo legislativo usual (KELSEN, 
1999, p. 157).

A grande preocupação da Teoria do Direito de Hans Kelsen vem transcrita em sua obra Teoria pura do direito:

[...] elevar a Jurisprudência, que - aberta ou veladamente - se esgotava quase por completo em raciocínios de política jurídica, à altura da genuína ciência. [...] empreendi desenvolver uma teoria jurídica pura, isto é, purificada de toda a ideologia política e de todos os elementos de ciência natural, uma teoria jurídica consciente da sua especificidade porque consciente da legalidade específica do seu objeto. (KELSEN, 1999, p. XII).

O princípio da pureza de Hans Kelsen, também conhecido como princípio da não valoração, veio para superar as confusões metodológicas e diferenciar o estudo do direito do estudo de outras ciências sociais, concedendo à ciência jurídica objeto e método próprios.

\section{A VALIDADE, EFICÁCIA E A NORMA FUNDAMENTAL}

A norma fundamental está no vértice do ordenamento jurídico, serve de validade de todas outras normas jurídicas:

\footnotetext{
A norma fundamental é a fonte comum da validade de todas as normas pertencentes a uma e mesma ordem normativa, o seu fundamento de validade comum. O fato de uma norma pertencer a uma determinada ordem normativa baseia-se em que o último fundamento de validade é a norma fundamental. (KELSEN, 1999, p. 136).
}

A norma que confere validade à última norma positiva do ordenamento, a Constituição, é a norma fundamental. Para Hans Kelsen, o Estado é hierarquizado, e a Constituição seria a norma superior, devendo-lhe obediência as demais normas. O direito natural era rejeitado por Hans Kelsen; sendo assim, o fundamento de validade da Constituição se situaria em outra norma, não escrita, de caráter hipotético, chamada de norma fundamental.

O conceito de Direito que realiza esse anseio por segurança, delimitando o fenômeno jurídico em relação à Moral e à Política, é o direito definido como sistema normativo, cujas categorias fundamentais são a validade e a norma fundamental. Esse sistema normativo é visto como uma fonte previsível de orientação à forma como o destinatário da norma deve conduzir-se. Hans Kelsen escreveu sua obra Teoria pura do direito definindo o direito como sistema normativo. 
A validade da norma deve distinguir-se de sua eficácia, do fato real de ela ser aplicada e observada. Hans Kelsen (1999, p. 8) reconhece que a eficácia é condição de validade da norma: “[...] uma norma jurídica é considerada como objetivamente válida apenas quando a conduta humana que ela regula lhe corresponde efetivamente, pelo menos numa certa medida".

O conceito de validade na obra de Hans Kelsen também é utilizado em outros sentidos, ou seja, dizer que a norma é válida significa dizer que ela vincula. "Dizer que uma norma que se refere à conduta de um indivíduo 'vale', significa que ela é vinculativa, que o indivíduo se deve conduzir do modo prescrito pela norma." (KELSEN, 1999, p. 135).

A determinação correta entre validade e eficácia é um dos problemas mais importantes e ao mesmo tempo mais difíceis de uma Teoria Jurídica Positivista; e apenas um caso especial da relação entre o dever-ser da norma jurídica e o ser da realidade natural.

Com efeito, também o ato com o qual é posta uma norma jurídica positiva é - tal como a eficácia da norma jurídica — um fato da ordem do ser. Uma Teoria Jurídica Positivista é posta perante a tarefa de encontrar entre os dois extremos, ambos insustentáveis, o meio-termo correto.

Um dos extremos é representado pela tese de que, entre validade como um dever-ser e eficácia como um ser, não existe conexão de espécie alguma, que a validade do Direito é completamente independente da sua eficácia. O outro extremo é a tese de que a validade do Direito se identifica com a sua eficácia. A primeira solução do problema tende para uma teoria idealista; a segunda, para uma teoria realista.

A primeira é falsa, pois, por um lado, não se pode negar que uma ordem jurídica como um todo, tal como uma norma jurídica singular, perde a sua validade quando deixa de ser eficaz; por outro lado, é também falsa porque existe uma conexão entre o dever-ser da norma jurídica e o ser da realidade natural, já que a norma jurídica positiva, para ser válida, tem de ser posta por meio de um ato-de-ser (da ordem do ser).

A segunda solução é falsa, pois não pode ser negado que há numerosos casos nos quais as normas jurídicas são consideradas como válidas se bem que não sejam eficazes.

A solução proposta pela Teoria Pura do Direito para o problema é: assim como a norma de dever-ser, como sentido do ato-de-ser que a põe, se não identifica com este ato, assim a validade de dever-ser de uma norma jurídica não se identifica com a sua eficácia da ordem do ser; a eficácia da ordem jurídica como um todo e a eficácia de uma norma jurídica singular são condição da validade. Tal eficácia é condição no sentido de que uma ordem 
jurídica como um todo e uma norma jurídica singular já não são consideradas como válidas quando cessam de ser eficazes. Mas também a eficácia de uma ordem jurídica não é, tampouco como o fato que a estabelece, fundamento da validade.

Fundamento da validade, isto é, a resposta à questão de saber por que devem as normas desta ordem jurídica ser observadas e aplicadas, é a norma fundamental pressuposta segundo a qual devemos agir em harmonia com uma Constituição efetivamente posta, globalmente eficaz, e, portanto, de harmonia com as normas efetivamente postas de conformidade com esta Constituição e globalmente eficazes.

A fixação positiva e a eficácia são pela norma fundamental tornadas condição da validade. A eficácia é, no sentido de que deve acrescer ao ato de fixação para que a ordem jurídica como um todo, e bem assim a norma jurídica singular, não percam a sua validade.

Uma condição não pode identificar-se com aquilo que condiciona. Assim, um homem, para viver, tem de nascer: mas, para permanecer com vida, outras condições têm ainda de ser preenchidas, por exemplo, tem de receber alimento. Se esta condição não é satisfeita, perde a vida. A vida, porém, não se identifica nem com o fato de nascer nem com o fato de receber alimento (KELSEN, 1999, p. 148).

No silogismo normativo que fundamenta a validade de uma ordem jurídica, a proposição de dever-ser que enuncia a norma fundamental: devemos conduzir-nos de acordo com a Constituição efetivamente posta e eficaz, constitui a premissa maior; a proposição de ser que afirma o fato: a Constituição foi efetivamente posta e é eficaz, quer dizer, as normas postas de conformidade com ela são globalmente aplicadas e observadas, constitui a premissa menor; e a proposição de dever-ser: devemos conduzir-nos em harmonia com a ordem jurídica, quer dizer: a ordem jurídica vale (é válida ou vigente), constitui a conclusão.

As normas de uma ordem jurídica positiva valem (são válidas) porque a norma fundamental que forma a regra basilar da sua produção é pressuposta como válida e não porque são eficazes; mas elas somente valem se esta ordem jurídica é eficaz, quer dizer, enquanto esta ordem jurídica for eficaz. Logo que a Constituição e, portanto, a ordem jurídica que sobre ela se apoia, como um todo, perde a sua eficácia, a ordem jurídica e com ela cada uma das suas normas perdem a sua validade (vigência). Uma ordem jurídica não perde, porém, a sua validade pelo fato de uma norma jurídica singular perder a sua eficácia, isto é, pelo fato de ela não ser aplicada em geral ou em casos isolados.

Uma ordem jurídica é considerada válida quando as suas normas são, numa consideração global, eficazes, são de fato observadas e aplicadas. E também uma norma 
jurídica singular não perde a sua validade quando apenas não é eficaz em casos particulares, isto é, não é observada ou aplicada, embora deva ser observada e aplicada.

Como já se acentuou a outro propósito, se fosse inadmissível a possibilidade de uma oposição entre o que uma norma estatui como devendo ser e o que de fato acontece, se houvesse uma norma que apenas estatuísse como devido (devendo ser) aquilo que de antemão sabemos que, segundouma lei natural, tem de acontecer, tal norma seria uma norma sem sentido, uma tal norma não seria considerada como norma válida. Por outro lado, também não se considera como válida uma norma que nunca é observada ou aplicada. E, de fato, uma norma jurídica pode perder a sua validade pelo fato de permanecer por longo tempo inaplicada ou inobservada, quer dizer, através da chamada desuetudo.

A desuetudo é como um costume negativo cuja função essencial consiste em anular a validade de uma norma existente. Se o costume é em geral um fato gerador de Direito, então também o Direito estatuído (legislado) pode ser derrogado através do costume.

Se a eficácia, no sentido acima, é condição da validade não só da ordem jurídica como um todo mas também das normas jurídicas em singular, então a função criadora de Direito do costume não pode ser excluída pela legislação, pelo menos quando se considere a função negativa da desuetudo.

A relação que acaba de ser descrita, entre validade e eficácia, refere-se às normas jurídicas gerais. Mas também as normas jurídicas individuais, através das quais, exemplo, através de uma decisão judicial ou de uma resolução administrativa, é ordenado um ato de coerção singular, perdem a sua validade quando permaneçam por longo tempo por executar e, portanto, ineficazes (KELSEN, 1999, p. 149). A eficácia é uma condição da validade, mas não é esta mesma validade. Isto tem de ser bem acentuado, pois não falta ainda hoje quem procure identificar a validade do Direito com a sua eficácia.

Essa tentativa, porém, está necessariamente condenada ao fracasso. Não só porque, também uma ordem jurídica ou uma norma relativamente ineficazes, quer dizer, ineficazes até certo ponto, podem ser consideradas como válidas, e uma norma absolutamente eficaz, que nem sequer pode ser violada, não é tida por válida porque nem sequer é considerada norma; mas especialmente porque, se se afirma a vigência, isto é, a específica existência do Direito, como consistente em qualquer realidade natural, não se está em posição de compreender o sentido próprio ou específico com o qual o Direito se dirige à realidade e pelo qual precisamente se contrapõe a essa realidade que - apenas se não se identifica com a vigência do Direito - , pode ser conforme ou contrária ao Direito. Assim como é impossível, 
na determinação da vigência, abstrair da realidade, assim também é impossível identificar a vigência com a realidade (KELSEN, 1999, p. 149).

Para Hans Kelsen, a ordem jurídico-positiva não é uma resposta categórica, mas uma resposta hipotética, condicionada: "Se considerarmos o direito positivo como válido então pressupomos a norma segundo a qual nos devemos conduzir tal como prescreve a primeira Constituição histórica em conformidade com a qual foi criada a ordem jurídica positiva." (KELSEN, 1993, p. 116).

A ordem jurídico positiva é merecedora de obediência pois foi criada por uma via legislativa ou consuetudinária, então objetivamente válida.

A grande questão enfrentada por Hans Kelsen é o fato de não ter a Constituição uma norma positivada que lhe conferisse validade jurídica. Entendeu Hans Kelsen que, diferentemente das demais normas jurídicas, a norma fundamental não surge de um órgão criador e não adquire validade por ter sido criada por um ato jurídico, mas simplesmente por ter sido pressuposta como válida, enquanto base de uma construção silogística das demais normas (KELSEN, 1998, p. 1).

A norma fundamental prescreve o dever de obedecer à autoridade, seja ela democrática ou não. Com isso, justifica-se qualquer ordem jurídica, transformando o direito em mero instrumento do poder político.

O direito é um emaranhado de normas que regulamenta as condutas sociais e são legitimadas pela norma fundamental, prescindindo de valoração legitimadora. Hans Kelsen ignora as ordens valorativas, não as considerando como necessárias ao aspecto jurídico, que por si só já contém os elementos necessários para a apreciação judicial.

O direito é fruto da vontade e não da razão, pois a razão estava desacreditada devido às descobertas científicas que acentuavam o conhecimento empírico.

O dualismo, direito positivo e direito natural, é insustentável, a depender da validade de uma ordem jurídica de conformidade e preceitos de um ideal de justiça situam numa esfera fora da ordem jurídica, é supor que exista uma moral absoluta e única à qual se deveria conformar o direito positivo.

\section{CRÍTICAS AO SISTEMA DE HANS KELSEN}

Os juristas também teciam críticas ao sistema kelseniano; como a Teoria Pura do Direito não está isenta de ideologias, ela pertenceria a uma doutrina positivista com sua 
crença de neutralidade axiológica.

As teorias sociológicas afastam-se da realidade e se impõem ao pretender exclusivamente descrever-se como uma teoria formal. Um exemplo, o jurista deve apenas descrever todas as interpretações possíveis de uma norma jurídica, sem escolher qual delas é a melhor.

As teorias jusnaturalistas direcionam as críticas contra a possibilidade de enquadramento de qualquer ordenação, à estrutura formal da Teoria Pura do Direito. Alguns autores antissemitas diziam que a teoria era vazia, formal e abstrata.

A separação entre direito e moral não é absoluta, sendo a moral fonte do direito em muitas relações jurídicas.

A normatividade era o objeto na teoria de Hans Kelsen e não emitia juízo de valor, pois ao trabalhar com valores o jurista tornaria um político.

A norma fundamental em que se baseia toda a construção do ordenamento jurídico, o direito existente é o direito posto e não pode ser posta, apenas pressuposta, é algo que o jurista aceita com base na sua valoração de justiça ou de oportunidade, em critérios subjetivos.

A norma fundamental, ao servir de fundamento para as demais normas, faz com que um elemento teórico da ordem do "ser" fundamente um elemento pertencente da ordem do "dever-ser", o que refuta a pureza metodológica, e a Teoria Pura do Direito tem na norma fundamental a emissão de um juízo de valor.

\section{FATO E ATO JURÍDICO}

Segundo Hans Kelsen, ao analisarmos qualquer fato jurídico, podemos distinguir dois elementos: primeiro, a sua manifestação externa como conduta humana realizada no tempo e no espaço perceptível sensorialmente; segundo, a significação que o ato tem do ponto de vista do Direito.

No ato de um indivíduo levantar a mão em uma reunião, o movimento do braço é o evento exterior, enquanto o significado jurídico pode ser a votação de uma lei.

Um fato pode ter um sentido subjetivo e um sentido objetivo. $\mathrm{O}$ ato de dispor de um patrimônio, por escrito, para depois da morte, pode apresentar-se, em sentido subjetivo, como sendo um testamento, mas, em sentido objetivo, não sê-lo, do ponto de vista do direito, por inobservância de forma, por exemplo. Portanto, o que transforma um fato num ato jurídico é 
o sentido objetivo, a significação que está ligada a esse ato. É a norma que fornece a esse fato o seu sentido objetivo jurídico, ao referir-se a ele como seu conteúdo. Logo, para se saber se um ato é jurídico devemos interpretá-lo normativamente, isto é, comparar o seu conteúdo com o conteúdo de uma norma.

A palavra norma significa que um homem deve conduzir-se de determinada maneira: ela não diz "este homem se conduzirá desta forma", e sim "este homem deve conduzir-se desta forma". Assim, a norma consiste no sentido de dever ser de um ato humano intencionalmente dirigido à conduta de outrem; porém esse sentido, para apresentar-se como jurídico, deve ser objetivo.

São os sentidos subjetivo e objetivo dos atos de vontade que permitem a diferenciação entre a ordem de um bandido para que lhe entreguemos determinada quantia em dinheiro da ordem de um funcionário público, cobrador de tributos, que nos exige um imposto. Somente esta ordem tem o sentido de norma, porquanto representa um ato que tem subjetiva e objetivamente o sentido de dever ser. Subjetivamente porque o dever ser é o sentido subjetivo de todo ato de vontade de um indivíduo que visa a conduta de outro, e objetivamente porque a conduta a que o ato se dirige (pagar impostos) é considerada devida, não apenas pelo autor do ato, mas também por terceiros.

A norma dirige-se intencionalmente à conduta alheia quando prescreve (comanda) uma conduta, quando a permite (autoriza), ou quando confere o poder de realizá-la (competência), em especial o poder de estabelecer normas. Assim, diz Hans Kelsen (1999, p. 4): "Norma é o sentido de um ato através do qual uma conduta é prescrita, permitida ou, especialmente, facultada, no sentido de adjudicada à competência de alguém." Em mais um pensamento de Hans Kelsen (1999, p. 135), "o fundamento de validade de uma norma apenas pode ser a validade de uma outra norma". Para o autor, a norma é vista como "uma ordem normativa da conduta humana, ou seja, um sistema de normas que regula o comportamento humano. Com o termo 'norma' se quer significar que algo deve ser ou acontecer" (KELSEN, 1999, p. 4).

A norma é a própria interpretação, levando o julgador a basear-se em enunciados legais.

Como visto, a Constituição estabelece limites da produção legislativa; a determinação normativa para Hans Kelsen nunca é completa, resta sempre uma margem de apreciação pelo julgador, dado o grau de indeterminação da lei.

Essa tal liberdade e subjetivismo do julgador pode ser limitada por uma moldura, "o 
Direito a aplicar a forma, em todas as hipóteses, uma moldura dentro da qual existem várias possibilidades de aplicação, pelo que é conforme ao Direito todo ato que se mantenha dentro deste quadro ou moldura, que preencha esta moldura em qualquer sentido possível" (KELSEN, 1997, p. 287).

Quando surge a interpretação de uma norma individualizada, Hans Kelsen chama de retratação da atividade jurisprudencial; assim, não havendo elementos filosóficos ou sociológicos, ele desconsidera normas de moral e éticas quando aplicadas ao caso concreto.

A interpretação jurídica, deve pautar-se em normas existentes, não podendo utilizarse da criação de novas normas, como faz a jurisprudência conceitual.

\section{A PIRÂMIDE DE HANS KELSEN}

A pirâmide de Hans Kelsen ajuda-nos a entender o sistema normativo jurídico brasileiro. Essa pirâmide foi concebida para fundamentar a sua teoria baseada na ideia de que as normas jurídicas inferiores (normas fundadas) retiram o seu fundamento da validade das normas jurídicas superiores (normas fundantes).

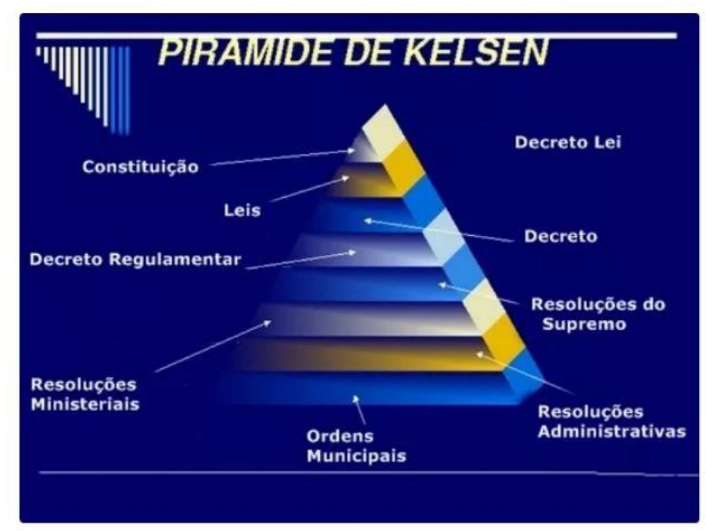

Figura 1

Fonte: ?

A Constituição brasileira é o vértice da pirâmide de Hans Kelsen, e nenhuma norma do ordenamento jurídico pode se opor a ela, sendo superior a todas as demais normas jurídicas, as quais são denominadas infraconstitucionais.

$\mathrm{Na}$ Constituição, há normas constitucionais originárias e normas constitucionais 
derivadas. As normas constitucionais originárias são produto do Poder Constituinte Originário, o poder que elabora uma nova Constituição.

As leis federais, estaduais, distritais e municipais possuem o mesmo grau hierárquico.

Em eventual conflito entre leis federais e estaduais ou entre leis estaduais e municipais não será resolvido por um critério hierárquico, a solução dependerá da repartição constitucional de competências.

A Constituição Federal está no patamar superior ao das Constituições Estaduais que, por sua vez, são hierarquicamente superiores às Leis Orgânicas.

\section{CONCLUSÃO}

Neste pequeno artigo, pudemos ver o Estado invocando para si a função de resolver os conflitos, através da Lei ou do reconhecimento de outros meios alternativos de resolução de conflito, além de um controle das normas consuetudinárias.

Hans Kelsen desenvolveu a sua Teoria Jurídica Pura do Direito sempre livre de ideologia política e de elementos da ciência natural, a qual chamou de pureza metodológica, também identificado de princípio da não valoração.

Também vimos o fundamento da norma fundamental, sendo a Constituição o vértice do ordenamento jurídico para Hans Kelsen. A norma fundamental seria a fonte comum da validade de todas as normas.

A validade, qualidade que expressa a existência de uma norma. Assumir que uma norma é válida significa dizer que ela existe.

Hans Kelsen também sofreu severas críticas contra a possibilidade de enquadramento de qualquer ordenação, destacando as teorias sociológicas e as teorias jusnaturalistas do direito, sempre criticando a realidade da Teoria Pura do Direito que impunha uma teoria formal.

Hans Kelsen também não abandonava a realidade quando ia definir a validade, pois precisava ser também eficaz. Ele dizia que sua teoria tinha por objeto a normatividade e não queria emitir juízos de valor; ao trabalhar com valores o jurista tornava-se um político.

Podemos destacar que a Teoria Pura do Direito ensina que o direito pode ser um fenômeno complexo, envolvendo não apenas normas, mas fatos e valores.

Os pensamentos de Hans Kelsen, embora com muitas divergências filosóficas, ainda servem de base para muitas decisões judiciais em todo o mundo. 


\section{REFERÊNCIAS}

BOBBIO, Norberto. O positivismo jurídico: lições de filosofia do direito. Tradução de Márcio Publiesi, Edson Bini, Carlos E. Rodrigues. São Paulo: Ícone, 1995.

KELSEN, Hans. O que é justiça? A justiça, o direito e a política no espelho da ciência. Tradução de Luis Carlos Borges e Vera Barkow. São Paulo: Martins Fontes, 1997.

KELSEN, Hans. O problema da justiça. Tradução de João Baptista Machado. São Paulo: Martins Fontes, 1993.

KELSEN, Hans. Teoria pura do direito. 6. ed. Tradução de João Baptista Machado. São Paulo: Martins Fontes, 1998.

KELSEN, Hans. Teoria pura do direito. 6. ed. [3. tiragem]. Tradução de João Baptista Machado. São Paulo: Martins Fontes, 1999. 